\title{
BMJ Open Comparison of immediate postpartum contraception among women with a high versus low risk pregnancy in Mexico: a retrospective cohort study
}

\author{
Jacqueline Powell (D) , ${ }^{1}$ Evelyn Fuentes-Rivera, ${ }^{2}$ Blair Darney ${ }^{1,3,4}$
}

To cite: Powell J, FuentesRivera E, Darney B. Comparison of immediate postpartum contraception among women with a high versus low risk pregnancy in Mexico: a retrospective cohort study. BMJ Open 2021;11:e048048. doi:10.1136/ bmjopen-2020-048048

- Prepublication history for this paper is available online To view these files, please visit the journal online (http://dx.doi org/10.1136/bmjopen-2020048048).

Received 20 December 2020 Accepted 23 June 2021

Check for updates

(c) Author(s) (or their employer(s)) 2021. Re-use permitted under CC BY-NC. No commercial re-use. See rights and permissions. Published by BMJ.

${ }^{1}$ Obstetrics and Gynecology, Oregon Health \& Science University, Portland, Oregon, USA ${ }^{2}$ Center for Health Systems Research, Instituto Nacional de Salud Publica (INSP), Mexico City, Mexico

${ }^{3}$ Center for Population Health Research, Instituto Nacional de Salud Publica (INSP), Mexico City, Mexico

${ }^{4}$ School of Public Health, Oregon Health \& Science University

- Portland State University,

Portland, OR, USA

Correspondence to

Dr Jacqueline Powell;

poweljac@ohsu.edu

\section{ABSTRACT}

Objective We tested whether women who reported highrisk pregnancies or deliveries were more likely to receive immediate postpartum contraception prior to discharge compared with normal-risk women in Mexico.

Methods This is a retrospective study using the National Health and Nutrition Survey. We classified women as high-risk based on reported complications in pregnancy and delivery. We used multivariable logistic regression to test the association of high-risk status and receipt of postpartum contraception (any modern method and Tier one methods) prior to discharge.

Results Our sample included 5030 deliveries (population $\mathrm{N}=3923657$ ). Overall, $19.1 \%$ of the sample were high risk. Over $60 \%$ of women in the high-risk and normal-risk group received immediate postpartum contraception, but a greater proportion of high-risk women received a method ( $67 \%$ vs $61 \%$ normal risk; $p<0.001)$. However, in multivariable models, there were no significant differences in receipt of any modern method or tier 1 method by risk group.

Conclusion Women with high-risk pregnancies were not more likely to receive postpartum contraception than the normal-risk group, once accounting for sociodemographic and clinical factors. Prenatal and postpartum contraception counselling should address the health effects of high-risk pregnancies and interpregnancy intervals to improve maternal health outcomes.

\section{INTRODUCTION}

Postpartum contraception is an integral component of obstetric care. The immediate postpartum period is an optimal time to provide contraception, especially for those women not able to follow up for postpartum care. ${ }^{1}$ Providing contraception prior to discharge from place of delivery is important to decrease the risk of short interpregnancy intervals (IPI) $(<18$ months), which are associated with increased maternal morbidity and mortality. ${ }^{2}{ }^{3}$ Morbidity associated with short interval pregnancies include higher rates of gestational diabetes, third trimester bleeding, preterm rupture of membranes, endometritis and anaemia. ${ }^{45}$ Both the risk of a short
Strengths and limitations of this study

Data were sourced from a publicly available nationwide survey that reflects population health data over a 6-year time period.

- The classification included many high-risk conditions that are recognised across the world.

- There was very little missing data.

- We controlled for sociodemographic status.

- Results are limited by the self-reported nature of the data.

interval pregnancy and the risks associated with short interval pregnancies are exacerbated for women with chronic conditions. Women with chronic medical conditions are at a higher risk of unintended pregnancies and a pregnancy in the setting of poor chronic disease control can lead to adverse pregnancy outcomes and disease progression. ${ }^{6}$ For example, women with gestational diabetes experiencing short interval pregnancies have an increased risk of developing type 2 diabetes mellitus in the future. ${ }^{7}$ It is important that women with pre-existing conditions and other complications of pregnancy or delivery have access to immediate postpartum contraception to reduce poor outcomes associated with a short interval pregnancy.

In Mexico, there are high rates of chronic medical conditions. Diabetes is responsible for $14 \%$ of all deaths in women, and when combined with cardiovascular complications, the disease accounts for $30 \%$ of total deaths in women. ${ }^{8}$ In addition, $71 \%$ of adults in Mexico and $30 \%$ of reproductive age women are obese, which is known to be associated with complications during the pregnancy. ${ }^{9} 10$ In Mexico, $94 \%$ of women deliver in facilities and therefore access to immediate postpartum contraception in a health facility is feasible for most of the population. ${ }^{11}$ 
While there is a large body of research on high-risk pregnancies, ${ }^{12}$ evidence about postpartum contraception in high-risk women or women with chronic conditions is more limited, especially in Mexico. Data on provision of postpartum contraception in this population are necessary to ensure high-risk women have access to effective contraception in order to ensure safe pregnancy spacing and prevent maternal morbidity and mortality. The purpose of this study is to test whether women who reported highrisk pregnancies or deliveries were more likely to receive immediate postpartum contraception prior to discharge. Our hypothesis is that women that have experienced a high-risk pregnancy and/or delivery have higher probabilities of using any contraceptive method, and specifically the most effective Tier 1 methods (implant, intrauterine device (IUD) or sterilisation). ${ }^{13}$

\section{METHODS}

This is a retrospective study using the 2018 round of the Encuesta Nacional de Salud y Nutricion/National Health and Nutrition Survey (ENSANUT), a publicly available population-based survey. ${ }^{14}$ ENSANUT is a face-to-face household survey that is performed every 6 years to evaluate population-level health in Mexico. Within this survey, women who report a live birth during the 6 years prior to survey (2012-2017) are asked about their prenatal care and delivery experience. All participants provide informed consent at the time of survey data collection. We included women of reproductive age (12-49 years old), who report a live birth the 6 years prior to the survey $(\mathrm{n}=5030)$ in our analysis.

The primary outcome was receipt of any modern contraceptive method prior to discharge from place of delivery. Our secondary outcome was focused on the use of a tier 1 contraceptive method, among the subsample who received a method. Tier 1 methods include the implant, IUD and sterilisation; tier 2 includes hormonal methods and tier 3 includes barrier methods. ${ }^{13}$ We decided to examine tier 1 methods specifically as this is the most effective method for preventing pregnancy. Additionally, in Mexico, tier 1 methods are overwhelmingly provided in the immediate postpartum setting; access to tier 1 methods is limited in a primary care setting and thus immediate postpartum access is crucial. ${ }^{1516}$

Our key independent variable was whether the woman experienced a high-risk pregnancy or delivery. We classified a woman as high risk if she reported any of the following conditions during pregnancy or delivery: diabetes, high blood pressure, eclampsia, haemorrhage or preterm birth. There were just 4 reported cases of HIV, all of whom had other comorbidities, so they are included in the high-risk group. ${ }^{17}$ Other conditions (urinary tract infection, anaemia, sexually transmitted infection, threatened abortion, and fetal malpresentation) were not included in our definition of high risk; these conditions are unlikely to increase maternal and infant morbidity and mortality in a subsequent pregnancy. For example, sexually transmitted infections and urinary tract infections can be treated with outpatient antibiotic regimens and with proper treatment are unlikely pose an increased risk to a subsequent pregnancy or to maternal health overall. ${ }^{18}$ We compared sample characteristics using highrisk definitions that included and excluded haemorrhage; there were no significant differences (data not shown) so we elected to retain haemorrhage in our definition of high risk to increase our sample size and because it is one of the leading causes of maternal death across the world. $^{19}$

We included additional sociodemographic and clinical information in our analysis. We included the woman's age at delivery $(<20,20-29,30-39,40$ and older), indigenous status (if the woman reports speaking an indigenous language) marital status (single, separated, divorced or widowed and married or cohabitating), educational gap in years defined as the difference between expected level of education based on age and actual current level of education (zero, one or two and three or more), parity (one child, two and three or more), place of delivery (social security/employment-based facility, Ministry of Health, private), type of birth (vaginal or caesarean delivery), education of household head (none or primary, secondary, high school and university or more), rural residence $(<2500$ habitants $)$ and socioeconomic quintile (1-5, with 1 being poorest, collapsed to 1 and 2 vs 3,4 and 5 in models), an index developed using principal components analysis and based on household materials and ownership of consumer goods which ranges from 1 to 5 with 1 being poorest. ${ }^{20}$ We had very little missing data.

\section{Cohort description and patient and public involvement}

The public was first involved in 2018 during survey enrollment for ENSANUT. This is a face-to-face household survey that is performed every 6 years to evaluate population-level health in Mexico. All participants provide informed consent at the time of survey data collection. Research questions were developed to assess for optimisation of contraception access in the immediate postpartum period. The public was not involved in the design of this study, as this data is publicly available and this is a nationwide survey. The public will not be involved in choosing methods and dissemination of study results. We thank the personnel involved in distributing and collecting the survey data.

\section{Analysis}

We used descriptive statistics to characterise the sample by pregnancy risk groups (normal risk and high isk). We next described proportions of individual complications and conditions during pregnancy and delivery. Next, we calculated crude outcomes (any contraceptive use and by Tiers) by risk group. Finally, we developed two logistic regression models to test the association of high-risk status and receipt of postpartum contraception prior to discharge. In the first model, we tested the association between risk status and use of any modern contraceptive 
method. In the second model, we restricted the sample to women who received a modern method and tested the association of risk status and use of a tier 1 method. Both models included age, parity, place of delivery, mode of delivery, educational gap, rural residence, socioeconomic quintile, marital status and indigenous status. All analyses used weights to account for the complex survey design; results can be interpreted as population estimates.

We performed two sensitivity analyses. First, we stratified our models by mode of delivery as caesarean delivery is known to be associated with receipt of tier one methods. ${ }^{11}$ Next, we excluded women who received immediate postpartum sterilisation in order to focus on reversible post-partum contraception. Our results were robust to these specifications and we present only our final models. We used Stata V.13 for all analyses (Stata).

\section{RESULTS}

Our final sample included 5030 deliveries ( $\mathrm{N}=3923$ 657). Overall $19.1 \%$ of the sample were classified as high risk. The largest age groups were 20-29 (43\%) and 30-39 $(39 \%) ; 10 \%$ of the sample were under 20 at the time of last birth and $8 \%$ over 40 years old (table 1 ). The majority

Table 1 Sample characteristics by risk group, in-facility deliveries Mexico 2012-2017

\begin{tabular}{|c|c|c|c|c|c|c|c|}
\hline \multirow[b]{3}{*}{ Contraception } & \multicolumn{2}{|c|}{ Overall } & \multicolumn{2}{|c|}{ Normal risk } & \multicolumn{2}{|c|}{ High risk } & \multirow{3}{*}{$\begin{array}{l}\chi^{2} \\
p \text { value* }\end{array}$} \\
\hline & \multicolumn{2}{|c|}{$100 \%(n=5030 ; N=3923657)$} & \multicolumn{2}{|c|}{$80.9 \%(n=4069 ; N=3198376)$} & \multicolumn{2}{|c|}{$19.1 \%(n=961 ; N=725281)$} & \\
\hline & Mean & $95 \% \mathrm{Cl}$ & Mean & $95 \% \mathrm{Cl}$ & Mean & $95 \% \mathrm{Cl}$ & \\
\hline$<20$ & 0.10 & 0.09 to 0.11 & 0.10 & 0.09 to 0.11 & 0.09 & 0.06 to 0.11 & 0.000 \\
\hline $20-29$ & 0.43 & 0.41 to 0.45 & 0.43 & 0.41 to 0.45 & 0.45 & 0.41 to 0.49 & \\
\hline 40-max & 0.08 & 0.07 to 0.09 & 0.08 & 0.07 to 0.09 & 0.08 & 0.06 to 0.10 & \\
\hline Indigenous & 0.07 & 0.06 to 0.08 & 0.08 & 0.06 to 0.09 & 0.04 & 0.03 to 0.06 & 0.009 \\
\hline Married & 0.78 & 0.76 to 0.79 & 0.79 & 0.77 to 0.81 & 0.72 & 0.68 to 0.76 & 0.000 \\
\hline \multicolumn{8}{|c|}{ Educational gap in years $†$} \\
\hline 0 & 0.77 & 0.75 to 0.79 & 0.77 & 0.75 to 0.79 & 0.78 & 0.74 to 0.82 & 0.302 \\
\hline Missing $(\mathrm{n}=70)$ & 0.01 & 0.01 to 0.02 & 0.01 & 0.01 to 0.02 & 0.02 & 0.01 to 0.03 & \\
\hline \multicolumn{8}{|l|}{ Parity } \\
\hline 1 & 0.33 & 0.31 to 0.34 & 0.32 & 0.30 to 0.34 & 0.36 & 0.32 to 0.40 & 0.000 \\
\hline 2 & 0.33 & 0.31 to 0.34 & 0.33 & 0.31 to 0.35 & 0.33 & 0.29 to 0.37 & \\
\hline 3 or more & 0.34 & 0.33 to 0.36 & 0.35 & 0.33 to 0.37 & 0.31 & 0.27 to 0.34 & \\
\hline \multicolumn{8}{|l|}{ Place of delivery $\ddagger$} \\
\hline Social security & 0.26 & 0.25 to 0.28 & 0.26 & 0.24 to 0.28 & 0.28 & 0.25 to 0.32 & 0.024 \\
\hline Ministry of Health & 0.49 & 0.47 to 0.51 & 0.49 & 0.47 to 0.51 & 0.50 & 0.46 to 0.54 & \\
\hline Private & 0.24 & 0.22 to 0.26 & 0.25 & 0.23 to 0.27 & 0.21 & 0.17 to 0.25 & \\
\hline 3 & 0.19 & 0.18 to 0.21 & 0.19 & 0.17 to 0.21 & 0.19 & 0.16 to 0.23 & \\
\hline 4 & 0.17 & 0.16 to 0.19 & 0.17 & 0.16 to 0.19 & 0.17 & 0.14 to 0.21 & \\
\hline 5 & 0.12 & 0.10 to 0.13 & 0.12 & 0.11 to 0.14 & 0.09 & 0.07 to 0.11 & \\
\hline Missing $(n=305)$ & 0.05 & 0.04 to 0.06 & 0.05 & 0.04 to 0.06 & 0.05 & 0.03 to 0.06 & \\
\hline
\end{tabular}

${ }^{\star} \mathrm{X}^{2}$ for group differences (normal risk and high risk including haemorrhage).

†Education gap in years is the difference in a woman's current education level from their age appropriate level.

$\ddagger \mathrm{n}=1$ missing observation. 
Table 2 Prevalence of specific complications within each risk group

\begin{tabular}{|c|c|c|c|c|c|c|}
\hline \multirow[b]{3}{*}{ Complication } & \multicolumn{2}{|c|}{ Overall } & \multicolumn{2}{|c|}{ Normal risk } & \multicolumn{2}{|c|}{ High risk } \\
\hline & \multicolumn{2}{|c|}{$100 \%(n=5030 ; N=3923657)$} & \multicolumn{2}{|c|}{$80.9 \%(n=4069 ; N=3198376)$} & \multicolumn{2}{|c|}{$19.1 \%(n=961 ; N=725281)$} \\
\hline & Mean & $95 \% \mathrm{Cl}$ & Mean & $95 \% \mathrm{Cl}$ & Mean & $95 \% \mathrm{Cl}$ \\
\hline Threatened abortion & 0.14 & 0.13 to 0.16 & 0.06 & 0.05 to 0.07 & 0.49 & 0.44 to 0.53 \\
\hline Diabetes & 0.02 & 0.01 to 0.03 & - & - & 0.12 & 0.09 to 0.14 \\
\hline Urinary infection & 0.14 & 0.12 to 0.15 & 0.06 & 0.05 to 0.07 & 0.46 & 0.42 to 0.51 \\
\hline STI & 0.00 & 0.00 to 0.01 & 0.00 & 0.00 to 0.00 & 0.01 & 0.00 to 0.02 \\
\hline HIV & 0.00 & -0.00 to 0.00 & - & - & 0.00 & -0.00 to 0.01 \\
\hline Other diseases & 0.02 & 0.01 to 0.02 & 0.01 & 0.01 to 0.01 & 0.05 & 0.03 to 0.07 \\
\hline Pre-eclampsia or eclampsia & 0.07 & 0.06 to 0.08 & - & - & 0.36 & 0.32 to 0.41 \\
\hline Malpresentation & 0.05 & 0.04 to 0.06 & 0.03 & 0.02 to 0.03 & 0.17 & 0.13 to 0.20 \\
\hline Preterm birth & 0.06 & 0.05 to 0.07 & - & - & 0.33 & 0.29 to 0.37 \\
\hline $\begin{array}{l}\text { Complications due a pre- } \\
\text { existing disease }\end{array}$ & 0.01 & 0.01 to 0.02 & 0.00 & 0.00 to 0.00 & 0.07 & 0.05 to 0.09 \\
\hline
\end{tabular}

STI, sexually transmitted infection.

of women $(78 \%)$ were married. Caesarean delivery was more common in the high-risk group (66\%) compared with normal risk $(43 \% ; \mathrm{p}<0.001)$. Half of the deliveries to both normal and high-risk women were in Ministry of Health facilities.

The most prevalent individual condition in our highrisk group was high blood pressure, reported by $63 \%$ of women in the high-risk group. Pre-eclampsia was reported by $36 \%$ of high-risk women and preterm birth by $33 \%$. Diabetes was reported by $12 \%$ of the high-risk population (table 2).

Over $60 \%$ of women in both the high risk and normalrisk group left place of delivery with a contraceptive method, but a greater proportion of high-risk women left
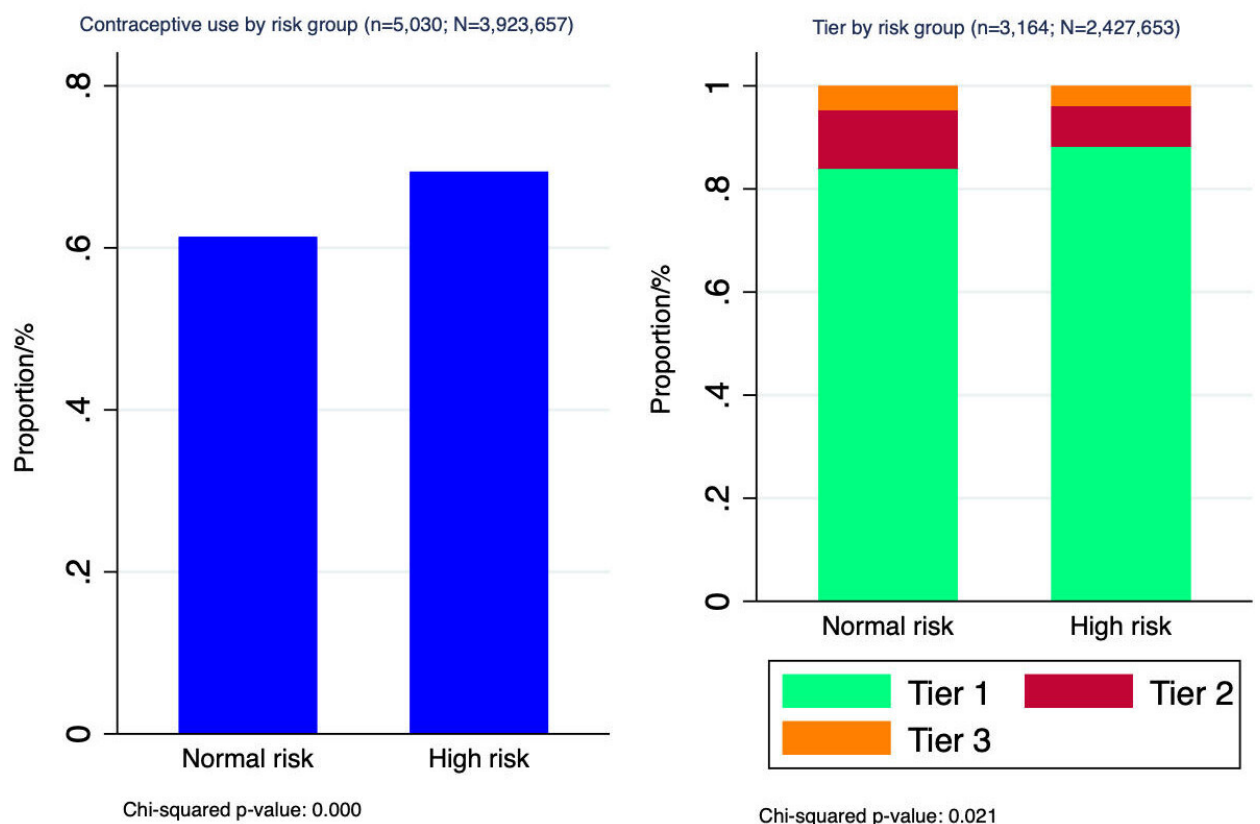

Data source, ENSANUT 2018

Chi-squared p-value: 0.021

Figure 1 Immediate postpartum contraceptive use by pregnancy risk status (any method and by Tiers among those receiving a method), Mexico 2012-2017. Data source, ENSANUT (2018). ${ }^{14}$ 
Table 3 Association between pregnancy risk status and immediate postpartum contraceptive use, Mexico 20122017

\begin{tabular}{|c|c|c|}
\hline & $\begin{array}{l}\text { Use of any modern } \\
\text { method }(n=5029) \\
N=3923068\end{array}$ & $\begin{array}{l}\text { Use of tier } 1 \\
(n=3164) \\
N=2427653\end{array}$ \\
\hline & OR & OR \\
\hline High risk & $\begin{array}{l}1.21 \\
(0.99-1.49)\end{array}$ & $\begin{array}{l}1.10 \\
(0.79-1.53)\end{array}$ \\
\hline \multicolumn{3}{|l|}{ Age } \\
\hline$<20$ & $\begin{array}{l}1.71^{\star \star} \\
(1.28-2.28)\end{array}$ & $\begin{array}{l}0.99 \\
(0.66-1.48)\end{array}$ \\
\hline 30-39 & $\begin{array}{l}0.82^{*} \\
(0.67-0.99)\end{array}$ & $\begin{array}{l}0.96 \\
(0.70-1.30)\end{array}$ \\
\hline 40-max & $\begin{array}{l}0.79 \\
(0.57-1.10)\end{array}$ & $\begin{array}{l}0.94 \\
(0.55-1.58)\end{array}$ \\
\hline \multicolumn{3}{|l|}{ Parity } \\
\hline Two & $\begin{array}{l}1.57^{\star \star} \\
(1.27-1.93)\end{array}$ & $\begin{array}{l}1.56^{\star \star} \\
(1.15-2.12)\end{array}$ \\
\hline Three or more & $\begin{array}{l}2.31^{\star \star} \\
(1.84-2.90)\end{array}$ & $\begin{array}{l}1.95^{\star \star} \\
(1.39-2.74)\end{array}$ \\
\hline \multicolumn{3}{|l|}{ Place of delivery } \\
\hline Social security & $\begin{array}{l}1.38^{\star \star} \\
(1.12-1.70)\end{array}$ & $\begin{array}{l}1.47^{\star} \\
(1.07-2.03)\end{array}$ \\
\hline Private & $\begin{array}{l}0.23^{\star *} \\
(0.19-0.28)\end{array}$ & $\begin{array}{l}0.56^{\star *} \\
(0.39-0.81)\end{array}$ \\
\hline Birth type (c-section) & $\begin{array}{l}1.49^{\star \star} \\
(1.26-1.78)\end{array}$ & $\begin{array}{l}2.03^{* *} \\
(1.54-2.67)\end{array}$ \\
\hline \multicolumn{3}{|l|}{ Educational gap in years } \\
\hline One or 2 years & $\begin{array}{l}0.94 \\
(0.65-1.35)\end{array}$ & $\begin{array}{l}1.84^{*} \\
(1.01-3.36)\end{array}$ \\
\hline Three or more years & $\begin{array}{l}0.77^{*} \\
(0.61-0.97)\end{array}$ & $\begin{array}{l}1.03 \\
(0.73-1.45)\end{array}$ \\
\hline Missing & $\begin{array}{l}1.06 \\
(0.57-1.98)\end{array}$ & $\begin{array}{l}1.13 \\
(0.36-3.57)\end{array}$ \\
\hline Rural (less than 2500 hab) & $\begin{array}{l}0.97 \\
(0.80-1.17)\end{array}$ & $\begin{array}{l}0.97 \\
(0.71-1.32)\end{array}$ \\
\hline Socioeconomic quintile & & \\
\hline 1 and 2 vs $(3,4$ and 5$)$ & $\begin{array}{l}1.08 \\
(0.92-1.29)\end{array}$ & $\begin{array}{l}1.01 \\
(0.77-1.32)\end{array}$ \\
\hline Marital status (Married) & $\begin{array}{l}1.09 \\
(0.90-1.33)\end{array}$ & $\begin{array}{l}0.67^{\star} \\
(0.49-0.93)\end{array}$ \\
\hline Indigenous & $\begin{array}{l}0.50^{\star *} \\
(0.37-0.66)\end{array}$ & $\begin{array}{l}1.22 \\
(0.69-2.16)\end{array}$ \\
\hline
\end{tabular}

$\mathrm{Cl}$ in brackets.

${ }^{* *} p<0.01,{ }^{*} p<0.05$

with a method ( $61 \%$ normal vs $67 \%$ high risk; $\mathrm{p}=0.000$; figure 1 left panel). Among the subsample of women who received a method (figure 1, right panel), $85 \%$ of normal-risk women received a tier 1 method compared with $88 \%$ of high-risk women $(\mathrm{p}=0.007)$. Among women who received a tier 1 method, sterilisation accounted for a third (33\%) in the normal-risk group compared with $38 \%$ of in the high-risk group ( $\mathrm{p}=0.000$; data not shown). A higher proportion of normal-risk women received IUDs compared with high-risk women (42\% normal risk vs $39 \%$ high-risk; $\mathrm{p}=0.011$, data not shown).

In our multivariable model controlling for sociodemographic and health system factors, there was no statistically significant difference in use of any modern method prior to discharge from place of delivery was by risk group (adjusted odds ratio, aOR=1.21, 95\% CI 0.99 to 1.49; table 3). Factors associated with receipt of immediate postpartum contraception were younger age (under 20 aOR $1.71,95 \%$ CI 1.28 to 2.28 , compared with 20-29 years old) and caesarean delivery ( $\mathrm{aOR}=1.49,95 \%$ CI 1.26 to 1.78). Use of tier 1 methods among those women who left place of delivery with a modern method was also not significantly different by risk group $(\mathrm{aOR}=1.10 ; 95 \%$ CI 0.79 to 1.53 ; table 3 ).

\section{DISCUSSION}

Our data show that overall in Mexico between 2012 and 2017, nearly one in five deliveries were to highrisk women. A slightly larger proportion of high-risk women left place of delivery with a contraceptive method compared with normal-risk women $(67 \%$ vs $61 \%)$. This difference was not statistically significant once we controlled for sociodemographic, clinical and health system factors, although it nears significance $(\mathrm{aOR}=1.21,95 \%$ CI 0.99 to 1.49$)$, suggesting that risk status may be associated with receipt of immediate postpartum contraception even accounting for sociodemographic, clinical and health system factors. Among women who received immediate postpartum contraception, a large majority received tier 1 methods ( $85 \%$ normal risk, $88 \%$ high risk).

Overall rates of immediate post-partum contraception have risen over time; the previous wave of ENSANUT (births from 2006 to 2012) showed that overall, 57\% of women left place of delivery with contraception. ${ }^{11}$ Our findings support this previous work that found that caesarean delivery was strongly associated with receipt of immediate postpartum contraception. ${ }^{11}$ However, this previous study did not examine high-risk pregnancies or comorbidities.

Postpartum contraception in high-risk pregnancies has not been previously well studied in Mexico. In a population of women with chronic medical conditions in the US, there was no difference in any postpartum contraception use between 2 and 6 months post partum compared with healthy women ${ }^{21}$; however, this study did not focus on immediate postpartum contraception. Our findings are similar to another study in a US sample that showed that while a higher proportion of high risk pregnancies had documentation of tier 1 contraceptives compared with normal-risk pregnancies, this difference did not persist 
when controlling for potential confounders. ${ }^{22}$ Among Medicaid enrollees with diabetes delivering in California, those with diabetes were more likely to receive permanent sterilisation than those without diabetes, however, among those who did not receive permanent sterilisation, less than half received reversible contraception in the postpartum period. ${ }^{23}$

We found that nearly one in five deliveries (19.1\%) in Mexico were to women with high-risk pregnancies or deliveries. Our definition of high risk is supported by the Society of Maternal Fetal Medicine ${ }^{6}$ and previous research which has used a binary classification as the basis for their analysis. ${ }^{21}$ Our proportion of high-risk pregnancies or deliveries is comparable to a US cohort studied in 2011 where $24 \%$ of women had a prepregnancy chronic disease, classifying them as high risk. ${ }^{21}$ In a cohort from Germany, $26.6 \%$ of pregnant women carried a diagnosis consistent with a chronic medical disease. ${ }^{24}$ Among women in our high-risk group, $12 \%$ had diabetes, similar to previously published data that estimates that gestational diabetes affects $10.3 \%$ of reproductive age women in Mexico. ${ }^{25}$ However, rates of type 2 diabetes mellitus are estimated at $13.6 \%$ of reproductive age women in Mexico, ${ }^{9}$ so our overall reported proportion with diabetes (gestational and exiting were not differentiated) is likely underestimated.

Our results must be interpreted with the following limitations in mind. First, our survey data rely on selfreported outcomes and exposures, and therefore, subject to recall bias. In previous work using the same data source, we found that limiting the sample to births within 2 years of the survey did not change results, ${ }^{10}$ suggesting that recall bias is limited. Second, the survey does not differentiate between gestational diabetes and pre-existing diabetes. It is likely that the prevalence of diabetes, gestational or pre-existing, is under-reported. Third, we do not know if women were counselled about immediate postpartum contraception and whether there was emphasis on patient education regarding high-risk pregnancies and avoiding a short IPI. Fourth, we do not have data on length of hospital stay in ENSANUT. Longer length of stay could be associated with pregnancy complications and with receipt of contraception and thus confound our findings. However, much contraception is provided at time of delivery-immediately post partum and would thus not be impacted by length of stay. ${ }^{11}$ Finally, while we have place of delivery, we do not have data on level of car of the health facilities where women delivered (primary care clinics vs secondary or tertiary hospitals). However, the norms in Mexico dictate that deliveries occur in hospital settings, so we do not anticipate this confounds our results.

\section{CONCLUSION}

We found that slightly larger proportion of high-risk women left place of delivery with a contraceptive method compared with normal-risk women; while this difference was not statistically significant once controlling for sociodemographic, clinical and health system factors, it neared significance which suggests that risk status may be associated with receipt of immediate postpartum contraception in Mexico. Women experiencing high-risk pregnancies should be counselled on the importance of avoiding short IPI and postpartum contraception. Avoiding short interval pregnancies is important to decrease maternal morbidity and mortality, and immediate postpartum contraception is a key intervention to prevent short IPI. This is especially important in Mexico where there are high rates of chronic medical conditions that can be exacerbated by pregnancy and increase pregnancyrelated morbidity and mortality. ${ }^{8-10}$ Specific counselling about the health effects of high-risk pregnancies, medical comorbidities and IPI should be standard to improve maternal health outcomes. ${ }^{6}$

Acknowledgements We thank all personnel involved in distributing and collecting data from the ENSANUT survey.

Contributors BD and JP conceived of the study, EF-R and BD conducted the analysis, JP drafted the manuscript, BD and EF-R reviewed the manuscript and contributed to the intellectual content.

Funding This research received no specific grant from any funding agency in the public, commercial or not-for-profit sectors. BD was partially supported by Society of Family Planning award SFPRF11-02.

\section{Competing interests None declared.}

Patient and public involvement Patients and/or the public were not involved in the design, or conduct, or reporting, or dissemination plans of this research.

\section{Patient consent for publication Not required.}

Ethics approval This secondary analysis of publicly available data was deemed non-human subjects research by the Oregon Health and Sciences University IRB prior to data analysis.

Provenance and peer review Not commissioned; externally peer reviewed.

Data availability statement Data are available in a public, open access repository. ENSANUT is a face-to-face household survey that is performed every 6 years to evaluate population-level health in Mexico. Within this survey, women who report a live birth during the 6 years prior to survey (2012-2017) are asked about their prenatal care and delivery experience. All participants provide informed consent at the time of survey data collection. We included women of reproductive age (12-49 years old), who report a live birth the 6 years prior to the survey $(n=5,030)$ in our analysis.

Open access This is an open access article distributed in accordance with the Creative Commons Attribution Non Commercial (CC BY-NC 4.0) license, which permits others to distribute, remix, adapt, build upon this work non-commercially, and license their derivative works on different terms, provided the original work is properly cited, appropriate credit is given, any changes made indicated, and the use is non-commercial. See: http://creativecommons.org/licenses/by-nc/4.0/.

ORCID iD

Jacqueline Powell http://orcid.org/0000-0002-3566-6115

\section{REFERENCES}

1 Speroff L, Mishell DR. The postpartum visit: it's time for a change in order to optimally initiate contraception. Contraception 2008;78:90-8.

2 WHO. Report of a who technical consultation on birth spacing. Rep a WHO Tech Consult Birth Spacing 2005;13:1-44 http://www.who.int/ maternal_child_adolescent/documents/birth_spacing.pdf

3 Moore Z, Pfitzer A, Gubin R, et al. Missed opportunities for family planning: an analysis of pregnancy risk and contraceptive method use among postpartum women in 21 low- and middle-income countries. Contraception 2015;92:31-9. 
4 Conde-Agudelo A, Belizan JM. Maternal morbidity and mortality associated with interpregnancy interval: cross sectional study. BMJ 2000;321:1255-9.

5 Hutcheon JA, Nelson HD, Stidd R, et al. Short interpregnancy intervals and adverse maternal outcomes in high-resource settings: an updated systematic review. Paediatr Perinat Epidemiol 2019:33:O48-59.

6 Vricella LK, Gawron LM, Louis JM. Society for Maternal-Fetal Medicine (SMFM) consult series \#48: immediate postpartum longacting reversible contraception for women at high risk for medical complications. Am J Obstet Gynecol 2019;220:B2-12.

7 Bernstein J, Lee-Parritz A, Quinn E, et al. After gestational diabetes: impact of pregnancy interval on recurrence and type 2 diabetes. Biores Open Access 2019;8:59-64.

8 Rull JA, Aguilar-Salinas CA, Rojas R, et al. Epidemiology of type 2 diabetes in Mexico. Arch Med Res 2005;36:188-96.

9 Gutierrez JP, Rivera-Dommarco J, Shamah-Levy T, et al. Encuesta nacional de salud Y nutricion 2012. Resultos Nacionales 2012.

10 Brenes-Monge A, Saavedra-Avendaño B, Alcalde-Rabanal J, et al. Are overweight and obesity associated with increased risk of cesarean delivery in Mexico? A cross-sectional study from the National survey of health and nutrition. BMC Preg Child 2019:19:1-11.

11 Darney BG, Sosa-Rubi SG, Servan-Mori E, et al. The relationship of age and place of delivery with postpartum contraception prior to discharge in Mexico: a retrospective cohort study. Contraception 2016;93:478-84

12 Zahn CM, Remick A, Catalano A, et al. Levels of maternal care verification pilot: translating guidance into practice. Obstet Gynecol 2018.

13 Stanback J, Steiner M, Dorflinger L, et al. WHO tiered-effectiveness counseling is rights-based family planning. Glob Health Sci Pract 2015;3:352-7.

14 INEGI. Encuesta Nacional de Salud Y Nutrición (ENSANUT), 2018. Available: https://www.inegi.org.mx/programas/ensanut/2018/
15 la V-SEde, Hubert C, Saavedra-Avendaño B. Provisión de métodos anticonceptivos en El posparto inmediato en México, 2018-19. Salud Publica Mex 2020;62:637-47.

16 Saavedra-Avendano B, Andrade-Romo Z, Rodriguez MI, et al. Adolescents and long-acting reversible contraception: lessons from Mexico. Matern Child Health J 2017;21:1724-33.

17 Eunice Kennedy Shriver National Institute. What are some factors that make a pregnancy high risk? 2018. Available: https://www.nichd nih.gov/health/topics/high-risk/conditioninfo/factors [Accessed 6 Jul 2021].

18 Connolly A, Thorp JM. Urinary tract infections in pregnancy. Infect Urol 1999:26:779-87.

19 Mousa HA, Walkinshaw S. Major postpartum haemorrhage. Curr Opin Obstet Gynecol 2001;13:595-603.

20 Cudeck R. Exploratory factor analysis. In: Handbook of applied multivariate statistics and mathematical modeling. San Diego, CA, US: Academic Press, 2000: 265-96.

21 Chor J, Rankin K, Harwood B, et al. Unintended pregnancy and postpartum contraceptive use in women with and without chronic medical disease who experienced a live birth. Contraception 2011;84:57-63.

22 French M, Albanese A, Gossett DR. Postpartum contraceptive choice after high-risk pregnancy: a retrospective cohort analysis. Contraception 2016;94:173-80.

23 Schwarz EB, Braughton MY, Riedel JC, et al. Postpartum care and contraception provided to women with gestational and preconception diabetes in California's Medicaid program. Contraception 2017;96:432-8.

24 Kersten I, Lange AE, Haas JP, et al. Chronic diseases in pregnant women: prevalence and birth outcomes based on the SNiP-study. BMC Preg Child 2014;14:1-13.

25 Reyes-Muñoz E, Castellanos-Barroso G, Ramírez-Eugenio BY, et al. The risk of gestational diabetes mellitus among Mexican women with a history of infertility and polycystic ovary syndrome. Fertil Steril 2012;97:1467-71. 